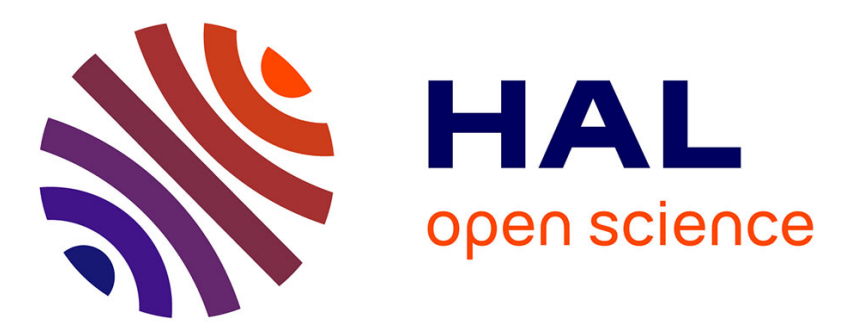

\title{
Physiological Responses of the Modified Shuttle Test in Adults With Cystic Fibrosis
}

Jean-Marc Vallier, Mehdi Rouissi, Laurent Mely, Mathieu Gruet

\section{To cite this version:}

Jean-Marc Vallier, Mehdi Rouissi, Laurent Mely, Mathieu Gruet. Physiological Responses of the Modified Shuttle Test in Adults With Cystic Fibrosis. Journal of Cardiopulmonary Rehabilitation and Prevention, 2016, 36, pp.288 - 292. 10.1097/hcr.0000000000000181 . hal-03566103

\section{HAL Id: hal-03566103 \\ https://hal-univ-tln.archives-ouvertes.fr/hal-03566103}

Submitted on 11 Feb 2022

HAL is a multi-disciplinary open access archive for the deposit and dissemination of scientific research documents, whether they are published or not. The documents may come from teaching and research institutions in France or abroad, or from public or private research centers.
L'archive ouverte pluridisciplinaire HAL, est destinée au dépôt et à la diffusion de documents scientifiques de niveau recherche, publiés ou non, émanant des établissements d'enseignement et de recherche français ou étrangers, des laboratoires publics ou privés. 


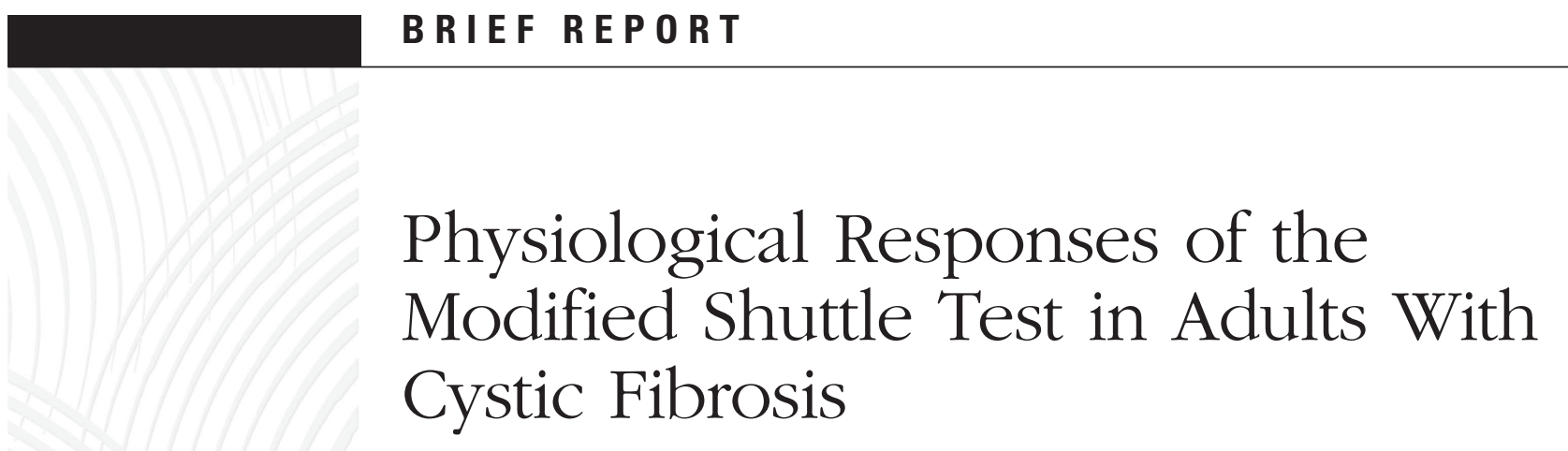

Jean-Marc Vallier, MD, PhD; Mehdi Rouissi, MSc; Laurent Mely, MD; Mathieu Gruet, PhD

PURPOSE: The modified shuttle test (MST) is increasingly used in clinical practice to assess functional capacity in patients with cystic fibrosis (CF). The purpose of this study was to evaluate the physiological responses of the MST in adults with CF as compared with the gold standard cardiopulmonary exercise test (CPET).

[AQ01]
METHODS: Participants performed an MST and a CPET on a cycle ergometer in random order. Oxygen $\left(\mathrm{O}_{2}\right)$ uptake $\left(\dot{\mathrm{V}}_{2}\right)$, carbon dioxide $\left(\mathrm{CO}_{2}\right)$ retention (end-tidal $\left.\mathrm{PCO}_{2} ; \mathrm{PETCO}_{2}\right)$, minute ventilation, heart rate, and peripheral $\mathrm{O}_{2}$ saturation $\left(\mathrm{SpO}_{2}\right)$ were continuously monitored. Whole blood lactate, dyspnea, and leg discomfort were recorded immediately after both exercises.

RESULTS: Twenty patients with CF (aged $33 \pm 8$ years; forced expiratory volume in 1 second $=48 \% \pm 17 \%$ ) completed both tests. Peak values for $\dot{\mathrm{V}}_{2}$ (27 \pm 7 vs $\left.24 \pm 6 \mathrm{~mL} / \mathrm{kg} / \mathrm{min}\right)$, heart rate $(169 \pm 19$ vs $163 \pm$ $16 \mathrm{bpm}$ ) and end $\mathrm{PeTCO}_{2}$ (42 \pm 7 vs $39 \pm 8 \mathrm{~mm} \mathrm{Hg}$ ), and $\mathrm{O}_{2}$ desaturation (end $\mathrm{SpO}_{2}, 86 \% \pm 7 \%$ vs $90 \% \pm 6 \%$ ) were significantly higher during the MST than during the CPET (all Ps $<.05$ ). Leg discomfort and whole blood lactate were significantly higher after the CPET (both $\left.P_{\mathrm{s}}<.05\right)$. Thirty-five percent and $40 \%$ of patients showed significant $\mathrm{O}_{2}$ desaturation and $\mathrm{CO}_{2}$ retention, respectively, during the MST, which was not detected during the CPET. A strong relationship was found between MST peak $\dot{V}_{\mathrm{O}_{2}}$ and body weight walking distance product $(r=0.90 ; P<.01)$.

CONCLUSIONS: The MST may provide a strong indicator of exercise tolerance in adults with CF as indicated by high peak $\dot{\mathrm{V}}_{2}$ values. In clinical practice, body weight walking distance should be considered as the primary outcome. This test is also better than cycle ergometry CPET for detecting $\mathrm{O}_{2}$ desaturation and $\mathrm{CO}_{2}$ retention, further emphasizing its clinical interest.

\author{
$\begin{array}{llllllll}K & E & Y & W & O & R & D & S\end{array}$ \\ cardiopulmonary function \\ chronic respiratory disease \\ exercise testing \\ modified walk test
}

\begin{abstract}
Author Affiliations: LAMHESS EA 6312, Universities of Toulon and Nice, SophiaAntipolis, France (Drs Vallier, Mely, and Gruet); Tunisian Research Laboratory "Sport Performance Optimization," National Center of Medicine and Science in Sports, Tunis, Tunisia (Mr Rouissi); and Regional Cystic Fibrosis Unit (CRCM), Renée Sabran Hospital, Giens, France (Dr Mely).
\end{abstract}

All authors have read and approved the submission of this manuscript.

The authors declare no conflicts of interest.

Correspondence: Mathieu Gruet, $\mathrm{PhD}$, LAMHESS EA 6312, Université de Toulon, BP 20132, 83957 La Garde, France (gruet@univ-tln.fr).

DOI: 10.1097/HCR.0000000000000181
Exercise has positive effects on many health outcomes in cystic fibrosis (CF), and higher levels of physical fitness are associated with better quality of life $^{1}$ and survival $^{2}$ in this population. A comprehensive and accurate assessment of exercise tolerance is thus fundamental in the clinical management of this population, including exercise rehabilitation. Maximal cardiopulmonary exercise test (CPET) performed on a cycle ergometer with gas exchange measurements is the gold standard exercise test. However, many centers do not have the resources to routinely include the $\mathrm{CPET}^{3}$ and performing the CPET using cycle ergometers may not reflect habitual physical activity of some patients. Peripheral muscle fatigue is often an important limiting factor during cycle CPET, ${ }^{4}$ so patients with significant muscle weakness may not achieve 
maximal cardiopulmonary stress. Moreover, treadmill walking tests are not interchangeable with hallway walking in patients with chronic respiratory disorders ${ }^{5}$ and thus may not be representative of real-life walking. Accordingly, it seems inappropriate to systematically generalize cycle ergometer CPET outcomes to everyday activities.

A number of field-based exercise tests have been used in CF, mainly because of their ease of use. The 6-minute walk test (6MWT) and the 3-minute step test are among the most popular. ${ }^{3,6}$ However, each test has its own limitations. The 6MWT requires substantial space (ie, 30-40 m) and may be less responsive to treatment than other externally paced tests. ${ }^{7}$ The reliability of the 3-minute step test has not yet been established in adults with CF, and important information (eg, oxygen $\left[\mathrm{O}_{2}\right]$ desaturation) may not be detected by this test. ${ }^{8}$ Eventually, both tests elicit submaximal responses and thus may not reflect the integrated response of the organism to exercise, nor identify the factors limiting exercise tolerance. ${ }^{8,9}$ The modified shuttle test (MST) is a field-based incremental walking/running test that is well-tolerated, reliable, and sensitive to antibiotic treatment. ${ }^{10,11}$ This test is simple to perform, necessitates minimal space, and is externally paced. Despite being increasingly used in clinical practice, ${ }^{3}$ only limited data are available on the physiological demands imposed on adults with CF during the MST.

The aim of the present study was to investigate the physiological responses of adults with CF during the MST as compared with the gold standard cycle ergometer CPET. Because of the specific breathing pattern and important muscle mass involved during walking/ running, we hypothesized that the MST, as compared with the CPET, would (1) elicit at least similar peak $\mathrm{O}_{2}$ uptake $\left(\dot{\mathrm{V}}_{2 \text { peak }}\right)$; and (2) induce greater $\mathrm{O}_{2}$ desaturation and carbon dioxide $\left(\mathrm{CO}_{2}\right)$ retention.

\section{METHODS}

Twenty adults with CF were recruited from a regional cystic fibrosis unit (CRCM, Respiratory Rehabilitation Center, Giens, France). Diagnosis of CF was based on clinical features and genotyping, according to standard guidelines. The patients were in a clinically stable state and had neither contraindications for maximal exercise testing nor significant orthopedic limitations limiting their ability to exercise. All subjects gave their written informed consent for the study, which was conducted according to the Declaration of Helsinki and approved by the local institutional review committee.

Patients performed a CPET and an MST in random order during 2 separate days within 1 week. The CPET was performed using an electrically braked cycle ergometer (Ergoselect 100; Ergoline GmbH, Bitz, Germany). Absolute workload increments (similar for all subjects) were chosen to permit optimal comparison with absolute increments imposed by the MST. After a 1-minute warm-up at 20 watts, the workload was increased by 6 watts per minute to obtain an exercise duration of at least 7 minutes in all patients, allowing optimal $\dot{\mathrm{V}}_{2 \text { peak }}$ determination according to recent recommendations. ${ }^{12}$ Subjects were instructed to maintain a cadence of 60 to $65 \mathrm{rpm}$ throughout the test. The MST was performed according to the 15-level protocol described by Bradley et al. ${ }^{11}$ Briefly, patients were required to walk/run at increasing speeds back and forth along a 10-m corridor. The test started with a speed of $1.8 \mathrm{~km} / \mathrm{h}$ (level 1), followed by an increment of 0.6 $\mathrm{km} / \mathrm{h}$ at each level. Each minute, patients were told to go a little faster and reminded that they were allowed to run at any time. The test ended when they were unable to maintain the set pace. Total distance and body weight distance product were calculated from the MST, and peak workload was determined from the CPET.

Expired gases were continuously measured during both tests using a breath-by-breath telemetric system (K4b2; Cosmed, Rome, Italy). $\mathrm{CO}_{2}$ production, minute ventilation $(\dot{\mathrm{V}} \mathrm{E}), \dot{\mathrm{V}}_{2}$, heart rate (HR) (RS 400; Polar Electro, Kempele, Finland), and peripheral $\mathrm{O}_{2}$ saturation $\left(\mathrm{SpO}_{2}\right)$ (Onyx Vantage 9590; Nonin Medical, Minneapolis, MN) were continuously monitored. Ventilatory threshold (VT) was visually determined using the modified V-slope method and ventilatory equivalents. Maximal predicted voluntary ventilation (MVV) was estimated as $37.5 \times$ forced expiratory volume in 1 second $\left(\mathrm{FEV}_{1}\right)$. The ratio peak $\dot{\mathrm{V}} / \mathrm{MVV}$ was calculated as an index of ventilatory limitation at peak exercise. Whole blood lactate was measured immediately after exercise from an ear-prick capillary sample and immediately analyzed using an enzymatic method (Lactate Pro; Arkray, Japan). Leg discomfort and dysp- [AQ02] nea sensations at peak exercise were measured immediately after both tests using a Borg 6-20 RPE scale. Significant $\mathrm{O}_{2}$ desaturation was defined as a $>5 \%$ fall of the resting $\mathrm{SpO}_{2}$ during the last minute of the CPET or MST. Significant $\mathrm{CO}_{2}$ retention was defined as a rise of $\geq 5 \mathrm{~mm} \mathrm{Hg}$ of end-tidal $\mathrm{PCO}_{2}\left(\mathrm{PeTCO}_{2}\right)$ from the initial workload until the peak workload. ${ }^{13} \mathrm{~A}$ test was considered to be at or near the maximal level if at least one of the following criteria was met: peak HR, $>85 \%$ predicted; peak respiratory exchange ratio, $>1.09$; sensations of leg discomfort or dyspnea, $>18$.

\section{Statistical Analysis}

Normality of distribution and homogeneity of variances of the main variables were verified using a Kolmogorov-Smirnov test and a Levene test, respectively. Paired $t$ tests and linear regression were 
performed to compare and investigate the relationships between CPET and MST outcomes, respectively. Statistical significance was set at $P<.05$. Results were reported as mean \pm standard deviation.

\section{RESULTS}

Participant characteristics and exercise data are summarized in the Table. Eight patients had severe lung dis- ease (defined as $\mathrm{FEV}_{1}<40 \%$ predicted), 8 had moderate lung disease $\left(\mathrm{FEV}_{1}=40-60 \%\right.$ predicted $)$, and 4 had mild lung disease $\left(\mathrm{FEV}_{1}>60 \%\right.$ predicted). Nineteen subjects had pancreatic insufficiency, and 5 had CF-related diabetes. According to the criteria previously stated, all patients performed both tests at or near maximal exercise. Fifteen patients ran during the MST, all starting between the seventh and ninth levels. $\dot{\mathrm{V}}_{2}$ $(+13.6 \%)$, respiratory rate $(+7.0 \%)$, and $\mathrm{HR}(+3.7 \%)$ were significantly higher at peak exercise during the

\section{Ta ble Participant Baseline Characteristics and Exercise Data ${ }^{a}$}

\section{Participant Characteristics}

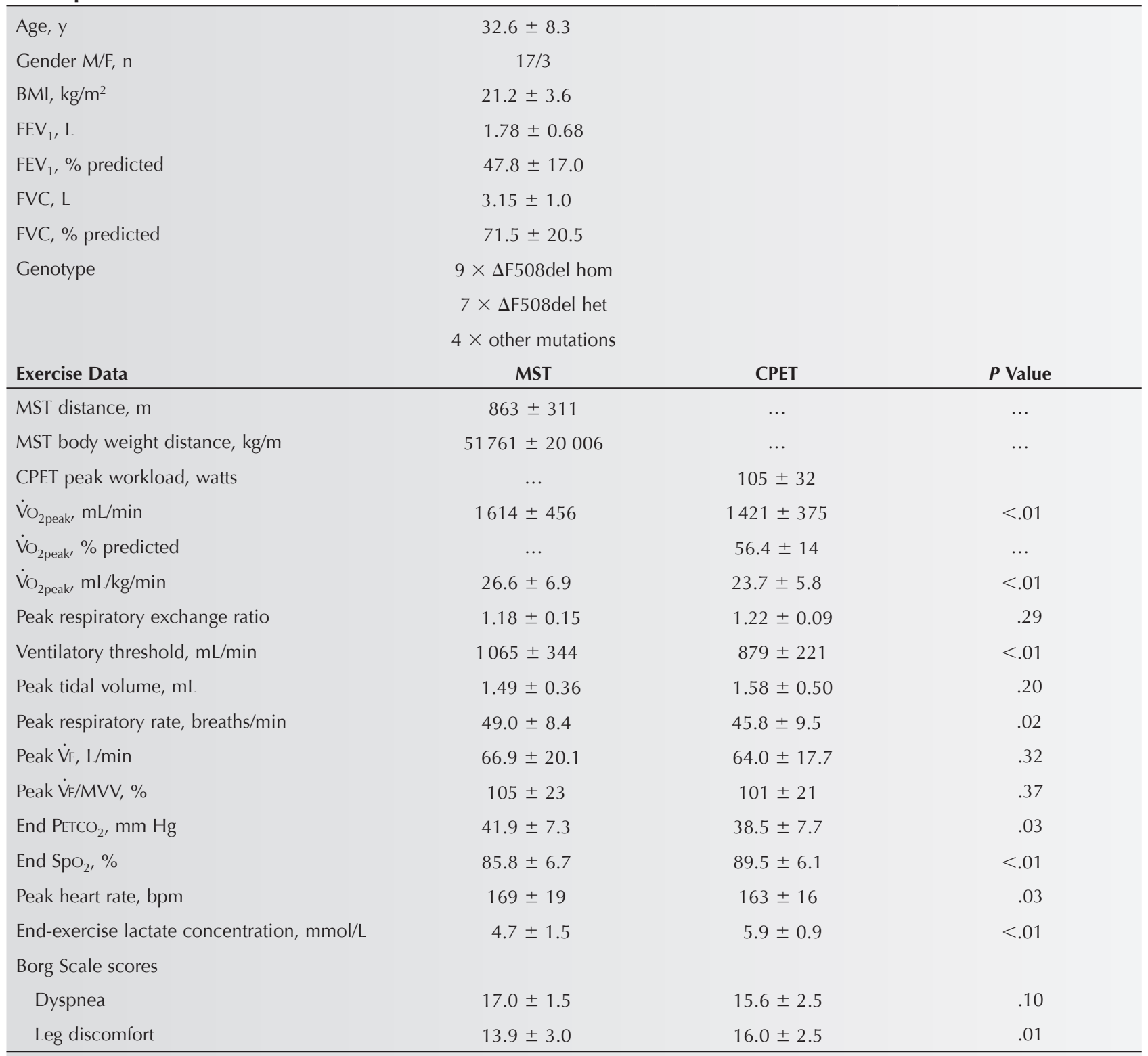

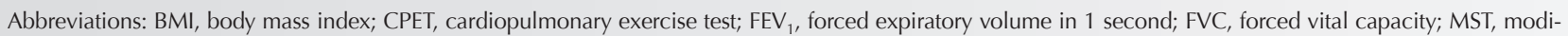
fied shuttle test; MVV, maximal predicted voluntary ventilation; $\mathrm{PETCO}_{2}$, partial pressure of end-tidal carbon dioxide; $\mathrm{SpO}_{2}$, peripheral oxygen saturation; $\dot{\mathrm{V}}_{\mathrm{E}}$ minute ventilation; $\dot{\mathrm{V}}_{2 \text { peak, }}$ peak oxygen consumption.

${ }^{a}$ Data are reported as mean $\pm \mathrm{SD}$, unless otherwise stated. 
MST than during the CPET (all $P s<.05$; Table). Peak lactate concentration $(+25.5 \%)$ and peak exercise leg discomfort $(+15.1 \%)$ were significantly higher after the CPET than after the MST (both $P S<.05$; Table). It was possible to determine VT in 16 patients during the MST and 19 patients during the CPET. Eight patients showed significant $\mathrm{O}_{2}$ desaturation during the CPET and 15 during the MST. Seven patients (35\% of the total population) showed significant $\mathrm{O}_{2}$ desaturation during the MST that was not detected during the CPET. Eight patients showed significant $\mathrm{CO}_{2}$ retention during the CPET and 14 during the MST. Eight patients (40\% of the total population) showed significant $\mathrm{CO}_{2}$ retention during the MST that was not detected during the CPET. Peak $\dot{\mathrm{V}}_{2}$ during the MST (MST $\left.\dot{\mathrm{V}}_{2 \text { peak }}\right)$ was strongly related to $\dot{\mathrm{V}}_{2 \text { peak }}$ measured during the CPET (CPET $\dot{\mathrm{V}}_{2 \text { peak }} ; r=$ 0.94; $P<.01)$. A stronger relationship was found between MST $\dot{\mathrm{V}}_{2 \text { peak }}$ and body weight distance product $(r=0.90 ; P<.01)$ than between MST $\dot{\mathrm{V}}_{2 \text { peak }}$ and total distance alone $(r=0.83 ; P<.01)$. Individual kinetics of $\dot{\mathrm{V}} \mathrm{E}$ and $\dot{\mathrm{V}}_{2}$ during the MST are shown in the Figure.
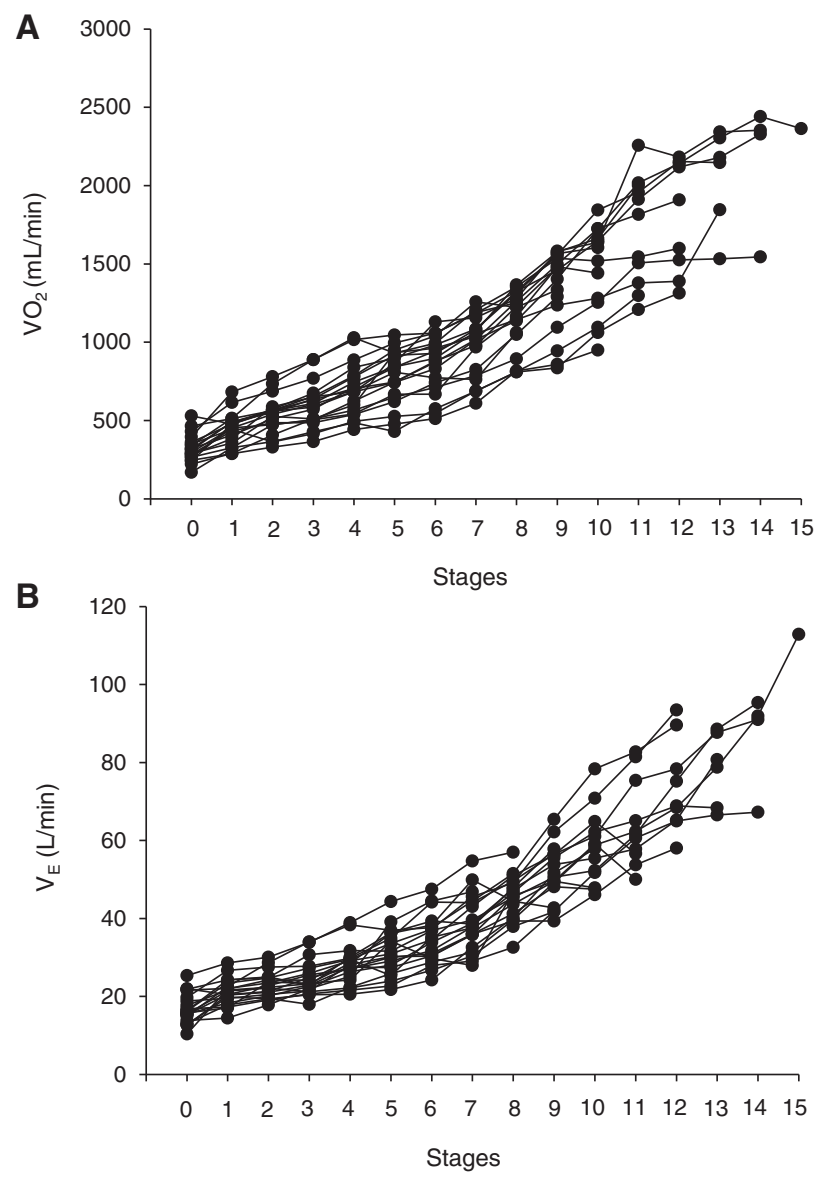

Figure. Physiological responses during the modified shuttle test at each stage. A, Individual data for oxygen uptake $\left(\dot{\mathrm{V}}_{2}\right)$. B, Individual data for minute ventilation $(\dot{\mathrm{V}})$.

\section{DISCUSSION}

This study described physiological responses to the MST as compared with the gold standard CPET in adults with CF. The main results are as follows: (1) the MST elicits higher $\dot{\mathrm{V}}_{2 \text { peak }}$ and (2) is better at detecting $\mathrm{O}_{2}$ desaturation and $\mathrm{CO}_{2}$ retention in $\mathrm{CF}$, compared with the CPET.

CPET $\dot{\mathrm{V}}_{2 \text { peak }}$ was $1.6 \pm 0.5 \mathrm{~L} / \mathrm{min}(56 \%$ of predicted values), which is consistent with previous studies investigating patients with CF with a similar degree of airway obstruction. ${ }^{14,15}$ The higher peak $\dot{\mathrm{V}}_{2}$ observed during the MST may be explained by the greater muscle mass involved in fast walking or running than in cycling on the ergometer. This assumption is supported by the higher peak HR values observed during the MST, resulting in increased muscle blood flow and the ability to match greater $\mathrm{O}_{2}$ demand due to higher muscle recruitment. These results differ from previous results in chronic obstructive pulmonary disease (COPD), where $\dot{\mathrm{V}} \mathrm{O}_{2 \text { peak }}$ and HR were similar between the CPET and the MST. ${ }^{16}$ In that study, the patients did not reach a speed requiring them to run and the MST was probably submaximal as indicated by low respiratory exchange ratio at peak exercise (ie, $0.82 \pm 0.01$ ) In the present study, $75 \%$ of patients reached speeds compatible with running, which may explain the greater cardiovascular demand of the MST in our study. As maximal exercise involves the integrated functioning of multiple organs in multisystem diseases such as CF, CPET $\dot{\mathrm{V}}_{2 \text { peak }}$ has been demonstrated to be one of the strongest markers of mortality in this population. ${ }^{2}$ In view of the high $\dot{\mathrm{V}}_{2 \text { peak }}$ values obtained during the MST, it is likely that this test has a high prognostic value in $\mathrm{CF}$, which remains to be evaluated. As body weight of the patients directly affects the walking/running efficiency, we calculated body weight distance product during the MST, as recommended during the 6MWT in COPD. ${ }^{17}$ This parameter demonstrated a strong and better association with MST $\dot{\mathrm{V}}_{2 \text { peak }}$ than with distance alone, suggesting that body weight distance should be chosen as the primary outcome of the MST. Larger studies across the spectrum of CF severity should be conducted to establish and validate an equation permitting to predict $\dot{\mathrm{V}}_{2 \text { peak }}$ from MST body weight distance.

$\dot{V} \mathrm{E}$ at peak exercise was not different between the MST and the CPET, despite slight differences in the breathing pattern (ie, similar tidal volume but slightly higher respiratory rate during the MST). Higher respiratory rate at peak exercise during the MST may be explained by a compensatory mechanism for the slightly higher sensation of dyspnea during this test. The absence of a difference in $\dot{\mathrm{V}} \mathrm{E}$ is probably due to 
the fact that patients reached their theoretical ventilatory limits in both tests (ie, ratio of peak $\dot{\mathrm{V}} \mathrm{E} / \mathrm{MVV}$ $\approx 100 \%$ ). Overall, our results indicate that MST performance is mainly limited by ventilatory factors whereas skeletal muscle function is also an important limiting factor during the CPET, as suggested by significantly higher perception of muscle fatigue and whole blood lactate as compared with the MST. Thus, these 2 tests measure different aspects of exercise tolerance in $\mathrm{CF}$ and should be considered complementary.

Another important result of the present study is the better ability of the MST to detect $\mathrm{O}_{2}$ desaturation and $\mathrm{CO}_{2}$ retention. This may have important clinical implications, as $\mathrm{O}_{2}$ desaturation during locomotor exercise is related to prescribing/adjusting $\mathrm{O}_{2}$ supplementation during ambulation and $\mathrm{CO}_{2}$ retention during exercise predicts a more rapid decline in pulmonary function in $\mathrm{CF}^{13}$ The arm muscles are active during fast walking and this may trigger reflex impulses to the respiratory centers, potentially leading to dyssynchronous breathing, and thus explains impairments in gas exchange during the MST. As fast walking and/or slow running are more representative of daily life activities than cycling, the MST should be a better alternative to the CPET to detect exercise-induced $\mathrm{O}_{2}$ desaturation and $\mathrm{CO}_{2}$ retention.

It was possible to determine a VT in $80 \%$ of the patients during the MST. Exercise at VT (eg, HR at VT) is one of the most popular and effective strategies to individualize endurance exercise intensity in patients with chronic respiratory disorders. Since VT for a given individual depends on exercise modality (eg, cycling vs running), determination of VT during the MST should be useful for individualizing the walking or running (ie, depending on patient disease severity) component of endurance rehabilitation program.

In conclusion, this study has demonstrated physiological adaptations peculiar to the MST in adults with CF. In a practical perspective, the body weight distance measured during the MST should be considered as the main outcome and measurement of $\mathrm{O}_{2}$ desaturation should allow for better detection of patients with $\mathrm{CF}$ who may exhibit $\mathrm{O}_{2}$ desaturation during ambulation. The MST performed with gas exchange measurements should be a strong indicator of physical fitness as indicated by higher $\mathrm{O}_{2 \text { peak }}$ values and may provide useful information about the ventilatory pattern and the likelihood of $\mathrm{CO}_{2}$ retention during dayto-day activities.

\section{-Acknowledgment-}

This study was financially supported by the Association Régionale d'Assistance Respiratoire à Domicile (ARARD).

\section{References}

1. Hebestreit H, Schmid K, Kieser S, et al. Quality of life is associated with physical activity and fitness in cystic fibrosis. $B M C$ Pulm Med. 2014;14(1):26.

2. Pianosi P, Leblanc J, Almudevar A. Peak oxygen uptake and mortality in children with cystic fibrosis. Thorax. 2005;60(1):5054.

3. Stevens D, Oades PJ, Armstrong N, Williams CA. A survey of exercise testing and training in UK cystic fibrosis clinics. J Cyst Fibros. 2010;9:302-306.

4. Moorcroft AJ, Dodd ME, Morris J, Webb AK. Symptoms, lactate and exercise limitation at peak cycle ergometry in adults with cystic fibrosis. Eur Respir J. 2005;25(6):10501056.

5. De Almeida FG, Victor EG, Rizzo JA. Hallway versus treadmill 6-minute-walk tests in patients with chronic obstructive pulmonary disease. Respir Care. 2009;54(12):1712-1716.

6. Holland AE, Rasekaba T, Wilson JW, Button BM. Desaturation during the 3-minute step test predicts impaired 12-month outcomes in adult patients with cystic fibrosis. Respir Care. 2011;56:1137-1142.

7. Pepin V, Brodeur J, Lacasse Y, et al. Six-minute walking versus shuttle walking: responsiveness to bronchodilation in chronic obstructive pulmonary disease. Thorax. 2007;62(4): 291-298.

8. Narang I, Pike S, Rosenthal M, Balfour-Lynn IM, Bush A. Threeminute step test to assess exercise capacity in children with cystic fibrosis with mild lung disease. Pediatr Pulmonol. 2003;35:108-113.

9. Ziegler B, Rovedder PME, Lukrafka JL, Oliveira CL, MennaBarreto SS, de Tarso Roth Dalcin P. Submaximal exercise capacity in adolescent and adult patients with cystic fibrosis. J Bras Pneumol. 2007;33(3):263-269.

10. Bradley J, Howard J, Wallace E, Elborn S. Validity of a modified shuttle test in adult cystic fibrosis. Thorax. 1999;54(5):437439 .

11. Bradley J, Howard J, Wallace E, Elborn S. Reliability, repeatability, and sensitivity of the modified shuttle test in adult cystic fibrosis. Chest. 2000;117:1666-1671.

12. Midgley AW, Bentley DJ, Luttikholt H, McNaughton LR, Millet GP. Challenging a dogma of exercise physiology: does an incremental exercise test for valid $\mathrm{VO}_{2}$ max determination really need to last between 8 and 12 minutes? Sports Med. 2008;38(6):441-447.

13. Javadpour SM, Selvadurai H, Wilkes DL, Schneiderman-Walker J, Coates AL. Does carbon dioxide retention during exercise predict a more rapid decline in $\mathrm{FEV}_{1}$ in cystic fibrosis? Arch Dis Child. 2005;90(8):792-795.

14. Thin AG, Linnane SJ, McKone EF, et al. Use of the gas exchange threshold to noninvasively determine the lactate threshold in patients with cystic fibrosis. Chest. 2002;121(6):17611770 .

15. Dodd JD, Barry SC, Gallagher CG. Respiratory factors do not limit maximal symptom-limited exercise in patients with mild cystic fibrosis lung disease. Respir Physiol Neurobiol. 2006;152:176-185.

16. Palange P, Forte S, Onorati P, Manfredi F, Serra P, Carlone S. Ventilatory and metabolic adaptations to walking and cycling in patients with COPD. J Appl Physiol (1985). 2000;88(5):17151720 .

17. Carter R, Holiday DB, Nwasuruba C, Stocks J, Grothues C, Tiep B. 6-minute walk work for assessment of functional capacity in patients with COPD. Chest. 2003;123(5):14081415 . 


\section{AUTHOR QUERIES}

TITLE: Physiological Responses of the Modified Shuttle Test in Adults With Cystic Fibrosis AUTHORS: Jean-Marc Vallier, Mehdi Rouissi, Laurent Mely, and Mathieu Gruet

[AQ01]: Would it be better to change "gold standard" to "criterion standard" throughout the text? Please advise. [AQ02]: Please provide the city location of Arkray. 